\title{
Alcançando as Metas de Enfermagem: na direção dos próximos 70 anos
}

\section{Elaine Larson ${ }^{1}$}

Sinto-me honrada ao escrever este editorial em reconhecimento do $70^{\circ}$ aniversário da Escola de Enfermagem da Universidade de São Paulo. O Jornal da Escola de Enfermagem da Universidade de São Paulo é um dos jornais de enfermagem mais prestigiados do Brasil e bastante citado em todo o mundo. Claramente, a missão tanto da Escola quanto do Jornal é compartilhada - incentivar a produção do conhecimento e a disseminação da ciência de enfermagem e avançar a prática de enfermagem por líderes educadores para a profissão. Evidências do comprometimento da Escola com o trabalho acadêmico são demonstradas nas publicações em português e inglês que descrevem as inovações e avanços educacionais da Escola e a pesquisa do corpo docente e alunos ${ }^{(1-3)}$. Os tópicos para pesquisa e colaborações da Escola são indicadores de seu alcance e perspectivas globais.

Devido ao fato de a profissão de enfermagem compartilhar metas em comum através de culturas e nações, vou aproveitar esta oportunidade para falar brevemente sobre um relatório recente publicado pelo The Institute of Medicine (IOM), The Future of Nursing: Leading Change, Advancing Health(4) - O Futuro da Enfermagem: Liderando Mudanças, Avançando a Saúde, que tem sido usado como um guia nos Estados Unidos para determinar as metas e objetivos da profissão de enfermagem para a próxima década. Com a meta de garantir que a profissão de enfermagem esteja preparada para assumir papéis de liderança para melhorar os cuidados ao paciente e sistemas de saúde, este Relatório identificou quatro mensagens relevantes e oito recomendações, como resumido no Quadro 1.

Quadro 1 - Principais mensagens e recomendações relacionadas do Relatório do IOM, The Future of Nursing - O Futuro da Enfermagem ${ }^{(4)}$

\begin{tabular}{|l|l|}
\hline Mensagem Principal & Recomendação \\
\hline $\begin{array}{l}\text { Enfermeiros devem praticar o máximo da educação e } \\
\text { treinamento }\end{array}$ & $\begin{array}{l}\text { 1. Retirar escopo das barreiras práticas } \\
\text { 2. Expandir as oportunidades para as enfermeiras liderarem e } \\
\text { espalharem os esforços de melhoria colaborativa } \\
\text { 3. Implementar programas de residência para enfermeiros }\end{array}$ \\
\hline $\begin{array}{l}\text { Enfermeiros devem alcançar níveis mais altos de } \\
\text { educação e treinamento através de melhores sistemas de } \\
\text { educação que promovam progressão acadêmica contínua }\end{array}$ & $\begin{array}{l}\text { 4. Aumentar a proporção de enfermeiros com bacharelado para } 80 \text { por } \\
\text { cento até 2020 } \\
\text { 5. Dobrar o número de enfermeiros com doutorado até 2020 }\end{array}$ \\
\hline $\begin{array}{l}\text { Enfermeiros devem ser parceiros completos com médicos } \\
\text { e outros profissionais de saúde na recriação da saúde. }\end{array}$ & $\begin{array}{l}\text { 6. Assegurar que os enfermeiros estejam envolvidos em aprendizado } \\
\text { por toda a vida }\end{array}$ \\
$\begin{array}{l}\text { 7. Preparar e permitir que enfermeiros liderem as mudanças para } \\
\text { melhorar a saúde }\end{array}$ \\
\hline $\begin{array}{l}\text { Planejamento eficaz da força de trabalho e preparação de } \\
\text { políticas, requerendo melhores coletas de dados e uma } \\
\text { melhor infraestrutura de informações. }\end{array}$ & $\begin{array}{l}\text { 8. Construir uma infraestrutura para a coleta e análise de dados da } \\
\text { força de trabalho interprofissional de saúde }\end{array}$ \\
\hline
\end{tabular}

\section{Barreiras ao alcance destas Metas}

Conforme mencionado no Relatório, enfermeiros trabalham em muitos ambientes e idealmente adaptam-se melhor para trabalhar como líderes em cuidados com a saúde. Há, no entanto, barreiras que impedem que sejam tão eficazes dentro do sistema de saúde como deveriam ou poderiam ser. Enquanto estas barreiras irão variar de país para país e de um ambiente para outro, há provavelmente alguns temas e desafios em comum encarados pela profissão em todo o mundo. Abaixo listo algumas destas barreiras e discuto as abordagens em potencial para a profissão seguir adiante.

Praticando ao máximo a nossa educação. Duas grandes barreiras para atingir esta meta incluem uma que é externa e outra que é provavelmente interna para a profissão. Primeiramente, está claro que há variações e limitações nos vários ambientes da prática que são impostos por motivos de licenciamento e regulamentação da prática. Remover essas barreiras irá frequentemente precisar de mudanças legislativas e reformas legais para melhorar a padronização e garantir que enfermeiros em todos os estados, países e ambientes estejam legalmente habilitados para praticar. Estas mudanças precisam de experiência política e parceria com pessoas em posição de influência política, incluindo instituições acadêmicas e líderes de enfermagem posicionados para serem eficazes em tais setores.

Igualmente importante, na minha opinião, no entanto, é a mentalidade e o comprometimento da profissão e os próprios enfermeiros individuais. Pode haver alguns enfermeiros que na realidade preferem NÃO assumir completamente o nível de responsabilidade, aprendizado e independência que o escopo completo da prática de enfermagem necessitaria. Em cada profissão, há membros que só estão cumprindo o tempo de trabalho para os quais a profissão é só um trabalho. Mas precisamos de líderes com voz que abracem totalmente não somente os benefícios, mas

${ }^{1}$ Professora de Pesquisa Farmacêutica e Terapêutica. Diretora Associada de Pesquisa, Escola de Enfermagem, Professora de Epidemiologia Escola Joseph Mailman de Saúde Pública da Universidade de Columbia, Editora do American Journal of Infection Control. Nova lorque, NY, USA. ell23@columbia.edu 
também as responsabilidades da profissão, e tais líderes vêm de programas de alta qualidade tais como os educados na Escola de Enfermagem da Universidade de São Paulo.

Alcançando níveis mais altos de educação. As habilidades essenciais para enfermagem cresceram nas últimas décadas para incluir a experiência em especialidades clínicas específicas e gestão de cuidados assim como liderança, trabalho em equipe interprofissional e colaboração, saúde da população, pesquisa e métodos de melhoria da qualidade, concepção e gestão de sistemas e política de saúde. E as coisas estão mudando muito rapidamente! Tal variedade de habilidades dinâmicas exige aprendizado e crescimento constantes e contínuos. O IOM sugere que isto irá requerer uma transição mais tranquila de um nível educacional ou graduação e o próximo; mais enfermeiros com doutorado; maiores esforços para garantir que a força de trabalho seja representativa das pessoas às quais servimos em termos de raça, gênero e etnia; e mais experiências educacionais com outros membros da equipe de saúde.

Por causa de nosso próprio comprometimento com a educação interdisciplinar, estabelecemos um programa de treinamento pré e pós-doutorado nos quais os treinandos de várias disciplinas interagem uns com os outros e com os mentores fora de suas próprias disciplinas ${ }^{(5-6)}$. Também desenvolvemos um curso de graduação, Interdisciplinary Research Models - Modelos de Pesquisa Interdisciplinar, que é oferecido para créditos acadêmicos em todas as escolas de saúde e escolas relacionadas em nossa Universidade ${ }^{(7)}$. Para garantir que as barreiras administrativas para o trabalho interdisciplinar sejam minimizadas, determinamos políticas e procedimentos para compartilhar recursos em todos os departamentos e escolas da universidade(8). Estes tipos de atividades são essenciais para continuar a movimentar a enfermagem dentro da investigação científica principal e papéis de liderança clínica.

Tornando-nos parceiros totais para reprojetar a saúde. Para tornar isto possível, não somente os programas de educação de enfermagem terão que incluir habilidades básicas em liderança, gestão e política, mas a profissão terá que abraçar maiores responsabilidades pela tutoria e desenvolvimento de seus líderes. Como o relatório do IOM sugere, a cultura da profissão deve promover e valorizar a liderança e crescimento pessoal e profissional.

Garantindo melhor coleta de dados e melhor infraestrutura de informação. Mesmo nos ambientes mais avançados e desenvolvidos de saúde, e apesar dos esforços nacionais e globais de melhorar a tecnologia de informação, registros eletrônicos de saúde e bancos de dados ainda não são a norma. Ainda menos comuns são os bancos de dados com relação à força de trabalho em saúde - ex. números, locais, especialidades, níveis educacionais dos enfermeiros. Com tantas prioridades competindo por recursos, é difícil justificar a coleta de dados em tempo oportuno e precisa sobre a força de trabalho de enfermagem, mas sem tais informações não é possivel projetar as necessidades ou fazer planos e recomendações convincentes para onde as brechas existem. Consequentemente há a recomendação de que sistemas sejam desenvolvidos e mantidos para que sejam capazes de caracterizar e localizar a força de trabalho de enfermagem.

Em resumo, as próximas décadas para a profissão de enfermagem irão provavelmente requisitar a aceitação de grandes desafios com vigor e compromisso renovados. Para a Escola de Enfermagem da Universidade de São Paulo e o seu Jornal, como líderes Brasileiros (e globais) em enfermagem, suas responsabilidades e oportunidades são grandes. Estou satisfeita de ser uma das muitas parceiras no seu trabalho e mais uma vez cumprimento-os nesta importante ocasião.

\section{Referências}

1. Riesco ML, Bonadio IC, Chande WG. Nursing School of the University of Sao Paulo and the Sao Paulo State Health Department: partners in the obstetric nursing specialization. Rev Esc Enferm USP. 2000;34(3):277-87.

2. Oguisso T, Tsunechiro MA. The University of São Paulo, School of Nursing's history of graduate program. Rev Esc Enferm USP. 2005;39(n.esp):522-34.

3. Oliveira MAC, Verissimo MDLOR, Puschel VA, Riesco MLG. Challenges in nursing education in Brazil: baccalaureate curricular proposal of the School of Nursing of Sao Paulo University. Rev Esc Enferm USP. 2007;41(n. esp):820-5.

4. U. S. Institute of Medicine. The future of nursing: leading change, advancing health [Internet]. Washington: The National Academies Press; 2001 [cited 2012 Mar 7]. Available from: http://www.iom.edu/Reports/2010/ The-Future-of-Nursing-Leading-Change-Advancing-Health.aspx

5. Columbia University. Center for Interdisciplinary Research to Prevent Infections. Training in Interdisciplinary Research on Antimicrobial Resistance (TIRAR) [Internet]. New York; 2012 [cited 2012 Mar 7]. Available from: http://www.nursing.columbia.edu/CIRAR/TIRAR.html

6. Larson EL, Landers TF, Begg MD. Building interdisciplinary research models: a didactic course to prepare interdisciplinary scholars and faculty. Clin Transl Science J. 2011;4(1):38-41.

7. Larson EL, Cohen B, Gebbie K, Clock S, Saiman L. Interdisciplinary research training in a school of nursing. Nurs Outlook. 2011;59(1):29-36.

8. Kulage KM, Larson EL, Begg MD. Sharing facilities and administrative cost recovery to facilitate interdisciplinary research. Acad Med. 2011;86(3):394-401. 